\title{
Análise das manifestações patológicas da ponte sobre o Rio Taquari em Araguatins/TO
}

As pontes são obras de arte que visam ultrapassar obstáculos e estabelecer a continuidade de uma via de qualquer natureza. Podem ser classificadas quanto sua finalidade (como rodoviárias, ferroviárias, passarelas), quanto seu material (concreto, madeira, metal e pedras) e quanto tipo estrutural (laje, viga, caixão, treliça, pórtico arco ou suspensa). Quando necessária em um sistema viário se tornam indispensáveis. A manutenção de estruturas consiste em um aglomerado de atividades, cujo objetivo é garantir o desempenho que na qual a estrutura foi projetada, de modo a preservar a sua vida útil. O objetivo deste trabalho foi identificar e abordar as manifestações patológicas sobre os elementos estruturais e acessórios de segurança da ponte sobre o Rio Taquari, situada no povoado Santa Tereza no município de Araguatins/TO. Foi feito uma averiguação do sistema construtivo, aferição das medidas e o detalhamento dos elementos da ponte. Posteriormente, foram feitas verificações visuais in loco onde classificou-se os componentes estruturais da ponte, com o intuito de identificar e abordar as respectivas patologias presentes e associadas aos mesmos. Este trabalho reforça a necessidade de intervenção de ações preventivas, por meio de inspeções rotineiras, uma vez que, a falta destas ações reduz a vida útil da estrutura.

\section{Analysis of pathological manifestations of the bridge over the Taquari River in Araguatins/TO}

\begin{abstract}
Bridges are works of art that aim to overcome obstacles and establish the continuity of a road of any nature. They can be classified according to their purpose (such as road, rail, walkways), material (concrete, wood, metal and stones) and structural type (slab, beam, casket, lattice, arch or suspended gantry). The maintenance of structures consists of a cluster of activities, whose objective is to guarantee the performance in which the structure was designed, in order to preserve its useful life. The objective of this work was to identify and discuss the pathological manifestations about the structural elements and safety accessories of the bridge over the Taquari River, located in the Santa Tereza settlement in the municipality of Araguatins/TO. A survey of the construction system, measurements and details of the bridge elements were made. Visual checks where the structural components of the bridge were classified in order to identify and address the respective pathologies present and associated with them. This work reinforces the need for intervention of preventive actions through routine inspections, since the lack of these actions reduces the useful life of the structure.
\end{abstract}

Keywords: Bridge; Inspection; Pathological Manifestations.

Topic: Engenharia Civil

Reviewed anonymously in the process of blind peer
Received: 07/12/2019

Approved: 21/02/2019
Franclin Lima de Sousa (iD)

Faculdade Católica do Tocantins, Brasil

http://lattes.cnpq.br/7236955640076866

http://orcid.org/0000-0001-7881-0554

eng.franclin@gmail.com

Flavio Vieira da Silva Junior (10)

Faculdade Católica do Tocantins, Brasil

http://lattes.cnpq.br/2211436659738090

http://orcid.org/0000-0002-7344-4679

junior vieira7@hotmail.com
Referencing this:

SOUSA, F. L.; SILVA JUNIOR, F. V.. Análise das manifestações patológicas da ponte sobre o Rio Taquari em Araguatins/TO. Engineering Sciences, v.8, n.1, p.45-56, 2020. DOI: http://doi.org/10.6008/CBPC2318-3055.2020.001.0006 


\section{INTRODUÇÃO}

Usadas desde tempos remotos, as mais antigas pontes foram construídas em Roma empregando a técnica de arcos de pedra aprendida com os etruscos. Existem relatos que os romanos também já utilizavam a madeira, com a técnica de treliças, para vencer vãos maiores (FELLIPE FILHO, 2008). As pontes são obras de arte que visam ultrapassar obstáculos e estabelecer a continuidade de uma via de qualquer natureza. A ponte propriamente dita é quando esse obstáculo é um curso de água ou outra superfície líquida (PFEIL, 1983).

Podem ser classificadas quanto sua finalidade (como rodoviárias, ferroviárias, passarelas), quanto seu material (concreto, madeira, metal e pedras) e quanto tipo estrutural (laje, viga, caixão, treliça, pórtico arco ou suspensa) (MARCHETTI, 2018). Quando necessário em um sistema viário, as pontes se tornam elementos indispensáveis. Basta retirar uma ponte de serviço ou restringir seu uso que acarreta perturbação no bom andamento do transporte rodoviário ou ferroviário. Por isso, que a manutenção das pontes se torna tão importante quanto seu processo construtivo (MILANI et al., 2012).

Manutenção de estruturas consiste em um aglomerado de atividades, cujo objetivo é garantir o desempenho que na qual a estrutura foi projetada, de modo a preservar a sua vida útil. A inexistência de manutenção preventiva ou corretiva é um dos principais fatores que ocasionam a redução da vida útil das pontes, podendo chegar até o colapso total da estrutura. Ainda que tenham sido bem construídas e com a utilização de materiais e equipamentos adequados, não garante a durabilidade e desempenho das estruturas, pois quando a inspeção de rotina é inadequada ou ineficiente permite a degradação das mesmas. (CAMPOS et al., 2018).

No Brasil essas inspeções devem ser realizadas conforme a NBR 9452 (2019) que trata sobre Vistoria de Pontes e Viadutos de Concreto. A ponte em estudo tem extensão de 30 metros, situa-se na Avenida Castelo Branco, no povoado Santa Tereza, na cidade de Araguatins/TO, transpõe o Rio Taquari e liga o Instituto Federal do Tocantins, Campus Araguatins à cidade. Foi construída em 1992, utilizando o método convencional, em concreto armado.

Este trabalho se caracteriza como um estudo de campo de cunho descritivo teórico-conceitual, construído através de realização de inspeção visual com visita no local do elemento em estudo. Nesse panorama, o objetivo do trabalho é identificar e abordar as manifestações patológicas sobre os elementos estruturais e acessórios de segurança da ponte.

\section{METODOLOGIA}

A metodologia adotada consistiu, inicialmente, na averiguação do sistema construtivo e aferição das medidas e o detalhamento dos elementos da ponte. Posteriormente, foram feitas verificações visuais in loco onde classificou-se os componentes estruturais da ponte, com o intuito de identificar e abordar e propor medidas corretivas às respectivas patologias presentes e associadas aos mesmos. Os instrumentos e equipamentos a realizar as coletas de dados foram: Máquina fotográfica; Trena; Paquímetro; Escada; Caneta; 
Papel; Prancheta. O estudo histórico da ponte foi feito com apoio do setor de jornalismo do Instituto Federal do Tocantins - Campus Araguatins, por meio de entrevistas a funcionários que testemunharam da execução da ponte na época de sua construção. Também foram ouvidos o setor de engenharia da prefeitura municipal.

\section{RESULTADOS E DISCUSSÃO}

\section{Área de estudo}

O elemento em estudo é uma ponte rodoviária executada em concreto armado. Está situada na Avenida Castelo Branco, na cidade de Araguatins - TO, a 5km do centro da cidade, no povoado Santa Tereza (Figura 1). Foi construída no ano 1992, devido à necessidade de melhorar condições de acesso de alunos e corpo docente à Escola Agrotécnica Federal de Araguatins, atual Instituto Federal do Tocantins - campus Araguatins, substituindo uma ponte de madeira.

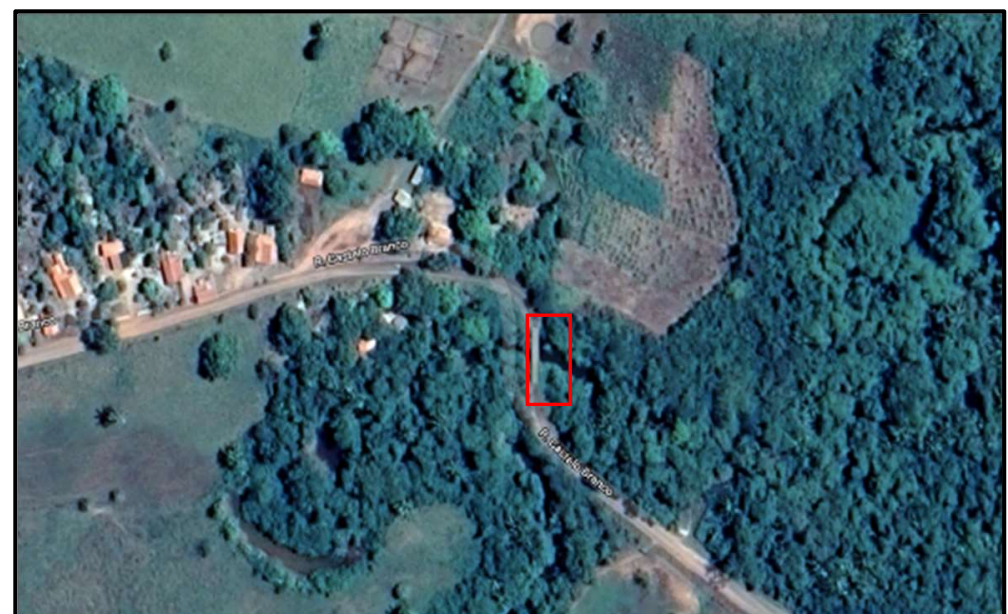

Figura 1: Localização do elemento em estudo. Fonte: Google Maps ${ }^{\circledR}$ (2019).

A via tem grande importância para a cidade, pois liga a maior instituição de ensino superior e técnico da região, esta que, movimenta a economia local. Deste modo, o fluxo de trânsito sobre a ponte esteve intrinsecamente ligado ao crescimento da instituição de ensino, que aumentou muito nos últimos anos. $A$ ponte não consta registro de sua construção e intervenções posteriores. Sua estrutura demonstra uma série de patologias que se deve, principalmente, à falta de manutenções preventivas e corretivas.

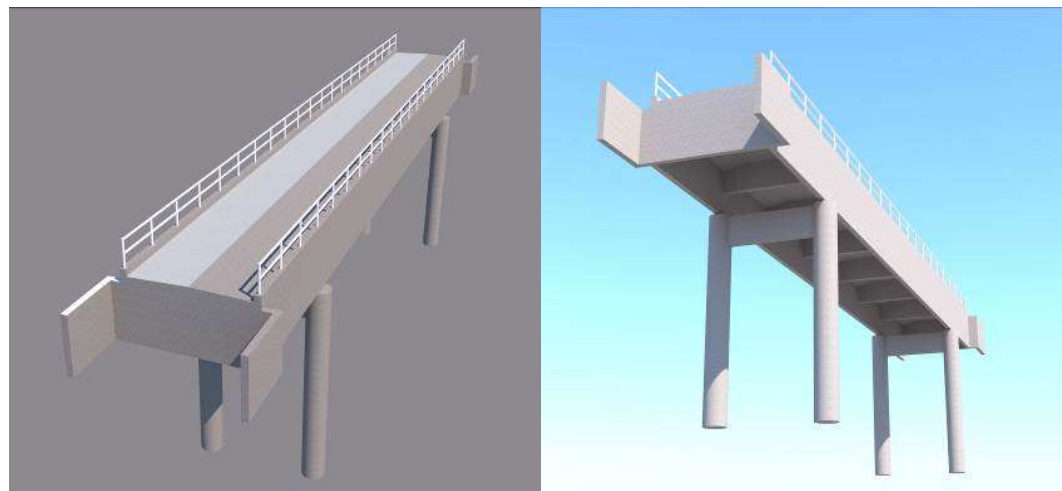

Figura 2: Modelo digital da ponte

Executada em concreto armado, a ponte tem comprimento de travessia total de 30 metros, largura 
total de 4 metros e não dispõe de passarela para pedestres. Sua superestrutura é composta por tabuleiros em lajes maciças com 20 centímetros de espessura, apoiadas sobre vigas longarinas de alma cheia com dimensões transversais de 2,2 metros de altura e 0,40 metros base, vigas transversinas de alma cheia com dimensões transversais de 0,80 metros de altura com 0,20 metros de base dispostas a cada 4 metros de vão, e guarda-corpos em tubos metálicos de 2,5 polegadas de diâmetro.

Com relação à mesoestrutura, é composta por quatro pilares circulares de 0,80 metro de diâmetro, dispostos em pares, e travados no topo por viga com dimensões transversais de 1,00 metro de altura com 0,30 metro de base. A infraestrutura é composta por estrutura de contenção de aterro, também conhecida por saia de aterro, disposta nas extremidades em balanço, e de fundações executadas em tubulão, com dimensões desconhecidas.

\section{Tabuleiro}

O tabuleiro é a estrutura responsável por resistir às cargas móveis e transferi às vigas. É composta por laje estrutural, pista de rolamento que pode ser de concreto ou asfalto. Sua estrutura deve obedecer ao projeto de drenagem. A pista deve ter $2 \%$ de caimento para que a água possa escoar até os drenos (DNIT, 2009). A ponte em estudo é constituída por pista única, permitindo a travessia de apenas um veículo por vez. A sua situação geográfica também é fator desfavorável, pois a ponte encontra-se em um trajeto sinuoso da rodovia, antecedendo e sucedendo curvas acentuadas.

A via apresenta dificuldade principalmente de passagens de veículos maiores, o que são frequentes, visto que, os alunos utilizam ônibus como principal meio de transporte da cidade à instituição de ensino. Sua estrutura é composta por laje estrutural, com capa de concreto na superfície. A mesma apresenta desgaste superficial, demonstrando alguns pontos de depressões. Além disso, apresenta acúmulo de solo e vegetação, evidenciando a presença de umidade (Figura 3).
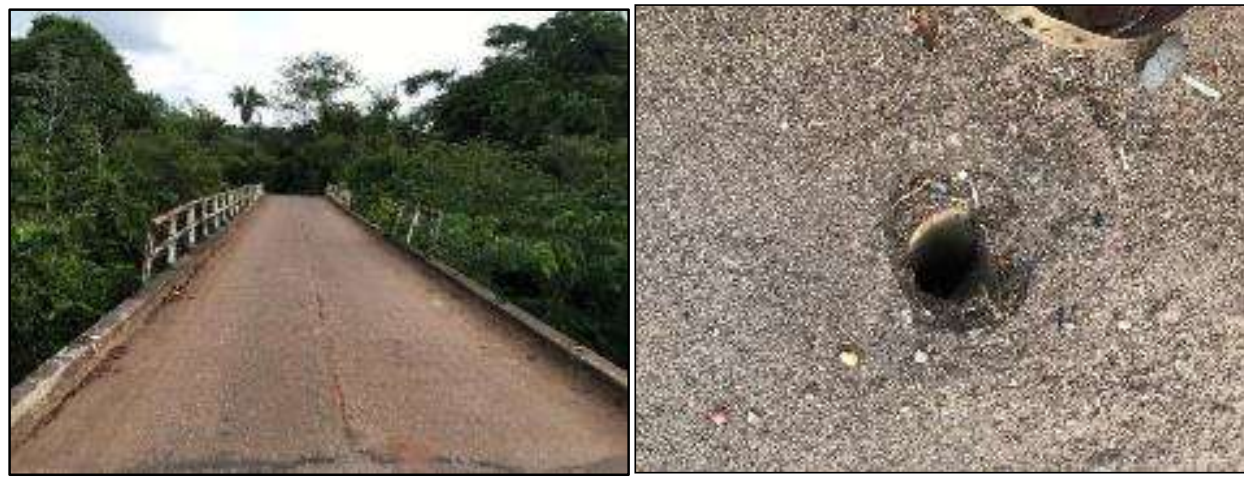

Figura 3: Tabuleiro da ponte em estudo.

O desgaste da superfície de concreto nas pistas de rolamento de uma ponte se deve à abrasão contínua de veículos, está interfere nas condições de transito sobre o tabuleiro, e sobre as condições necessárias para a drenagem, o que também interfere nas condições de segurança do tráfego (DNIT, 2004). Faz-se, portanto, necessário a reparação do pavimento, através do recapeamento com concreto asfáltico, afim que seja feita a regularização superficial, gerando mais conforto na rodagem. $\mathrm{O}$ tabuleiro apresenta 
também armaduras de flexão expostas na parte inferior, devido à falta de cobrimento de concreto nas armaduras (Figura 4). Esta patologia é causada pela falta do uso de espaçadores durante a execução da laje.

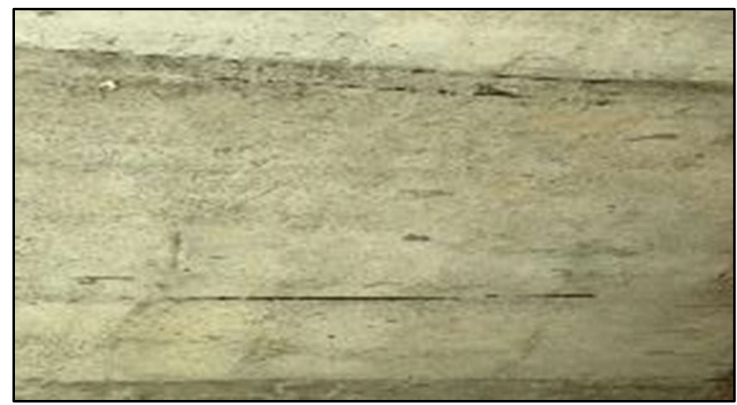

Figura 4: Armaduras expostas na parte inferior do tabuleiro.

Segundo a NBR 6118 (ABNT, 2014) a durabilidade do concreto armado está intrinsecamente ligada ao cobrimento das armaduras no concreto, o que garante a proteção contra os agentes ambientais. Apesar da existência da patologia, não há sinais de que esteja gerando insuficiência estrutural, porém, o tratamento deve ser realizado, afim de evitar uma maximização do problema. Deste modo, é necessário a aplicação de produto anticorrosivo sobre as armaduras e preenchimento com argamassa de reparo estrutural.

\section{Dispositivos de segurança}

Os guarda-corpos são de tubos metálicos de 2,5 polegadas e apresenta bastante danificado. Como mostra a figura 5, o dispositivo encontra-se completamente oxidado e em parte inexistente. A patologia está em estado avançado, e a estrutura com insuficiência de suporte. A falta de manutenção é o principal fator causador da patologia.

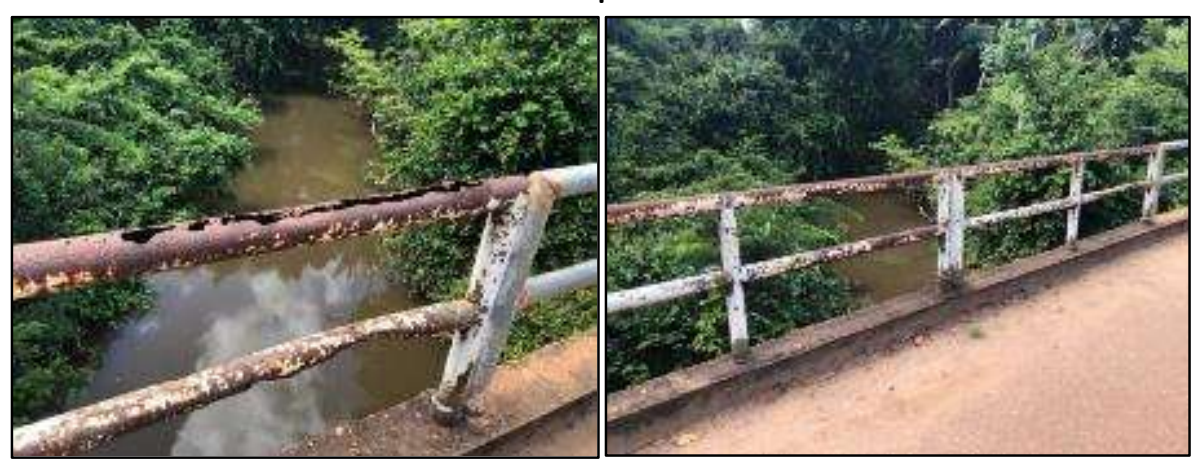

Figura 5: Guarda-corpos oxidados.

Pelo fato de elemento de estudo não possuir via lateral para pedestres, a ineficiência desse acessório torna a ponte bastante perigosa para o tráfego de pedestres. Apesar de se situar em uma curva sinuosa, a ponte não possui barreiras ou dispositivos de segurança lateral contrachoques nas entradas da ponte. Assim, percebe-se que os guarda-corpos devem ser substituídos e feita a instalação de proteção lateral, a exemplo as defensas, nos trechos curvos nas entradas da ponte, para evitar que os veículos sejam lançados fora da pista, visto que, trata-se de um encurtamento da pista dupla da rodovia para a pista única da ponte. 


\section{Sinalização}

Em termos gerais, a sinalização de rodovias deve conquistar a atenção e a segurança do usuário, proporcionando-Ihe um tempo de reação suficiente. Esse objetivo dá-se pelo uso de sinais e marcas em dimensões e locais apropriados. A sinalização permanente constitui-se num sistema de dispositivos fixos de controle de tráfego que, ao serem implantados, ordenam, advertem e orientam os seus usuários (DNIT, 2010).

Deste modo, é possível afirmar que a correta sinalização é capaz de alertar a possíveis condições da via que exigem maior atenção, de não percepção visual antecedente. Este sistema tem principal função alertar condutores afim de evitar acidentes, e a falta deste tem efeito reverso. A ponte em estudo não dispõe de sinalizações balizadoras, de advertência ou de indicação. Além disso, conta com agravante, por situar-se em trecho sinuoso da via, estando intercalada por duas curvas acentuadas também desprovidas de sinalização tanto verticais como horizontais e ainda há presença de vegetação próximo as margens, o que dificulta mais a visualização.

A figura 6 mostra as duas extremidades da ponte. Em que, a figura 16.a indica, na chegada da ponte sentido ao IFTO, sinalização de indicação, porém, encontra-se desgastada pelo tempo, sem pintura, sendo difícil percepção aos usuários, e a figura 6.b, chegada da ponte sentindo à cidade, está destituída de sinalização.

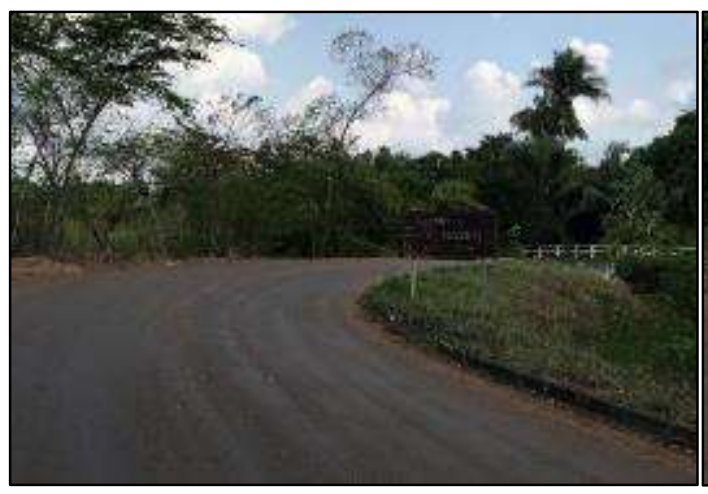

a)

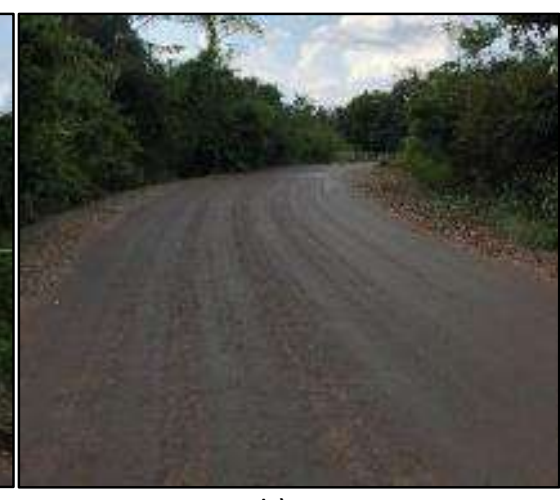

b)

Figura 6: Ausência de sinalização da ponte.

É necessário, portanto, a implantação da completa sinalização. A sinalização horizontal, como pintura de linhas de retenção e divisão de transito na rodovia que dá acesso, e sinalização vertical, com placas de regulamentação, advertência e indicação. Ainda, principalmente por se tratar de um trecho em curvas, a sinalização balizadora refletiva é imprescindível, assim como no trecho antecedente curvo.

\section{Sistema de drenagem}

Segundo DNIT (2009) o sistema de drenagem de pontes deve estar com condições de drenar ligeiramente as águas provenientes das chuvas, afim de evitar acúmulos sobre o tabuleiro prevenindo de umidade e riscos de acidentes ocasionados pela aquaplanagem dos veículos. A presença de umidade prolongada no concreto propicia o processo de degradação do mesmo. A ponte em estudo dispõe de 
tabuleiro com declividade para as bordas onde se distribuem drenos em tubos PVC de $7 \mathrm{~cm}$ de diâmetro, com pontas em bisél, a cada 4 metro ao longo da ponte, conforme a figura 7.

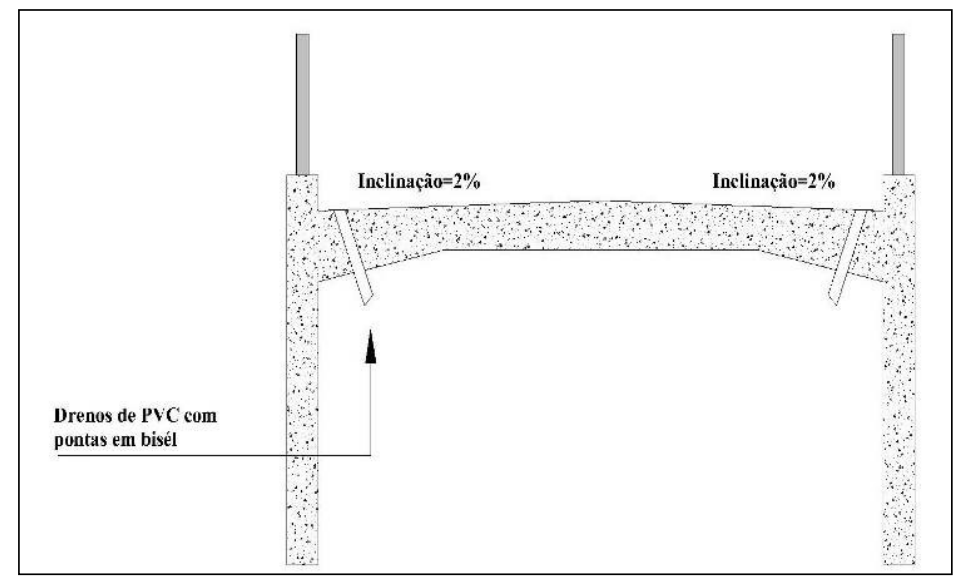

Figura 7: Corte transversal da ponte em estudo.

A Figura 8 mostra a existência de manchas escuras ocasionadas por fungos devido à presença de umidade, esse fator deve-se ao mal funcionamento do dreno, especialmente, por falta de comprimento do tubo após a laje.
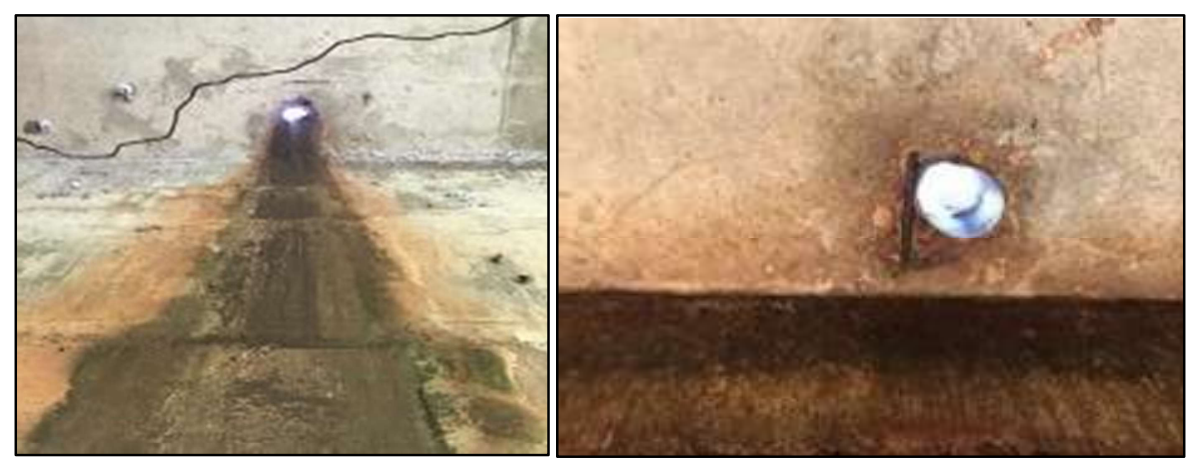

Figura 8: Manchas escuras devido a presença de fungos.

Os drenos também apresentam diâmetros insuficientes, com a apenas 7 centímetros de diâmetro, o que propicia o entupimento e prejudica o bom funcionamento do escoamento da água (Figura 9).

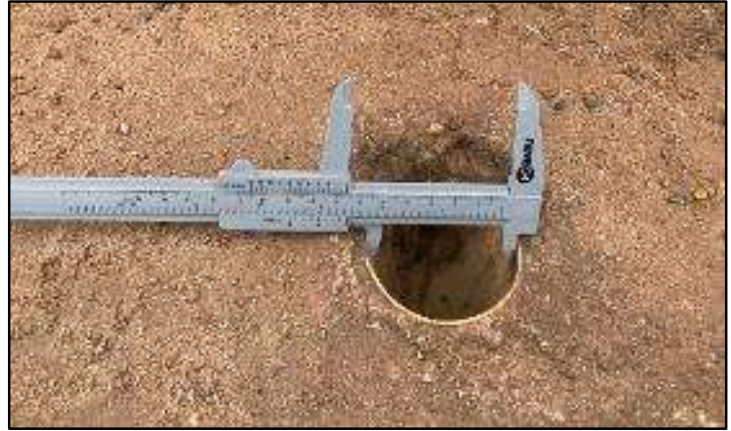

Figura 9: Diâmetro insuficiente do dreno.

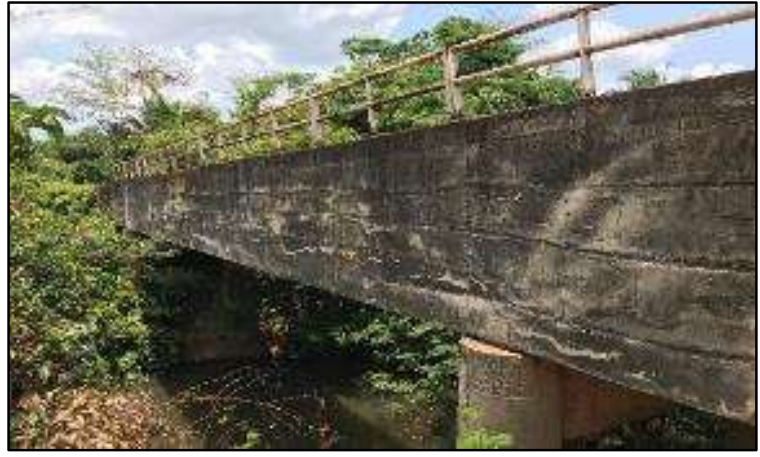

Figura 10: Manchas escuras na face externa da viga longarina.

Segundo (DNIT, 2009) os drenos da pista de rolamento constituídos de PVC devem ter diâmetros de no mínimo $10 \mathrm{~cm}$ e exceder da estrutura no mínimo $15 \mathrm{~cm}$, com pontas em bisel. Devem estar espaçados no máximo 4 metros de distância entre si. Para o reparo do sistema é necessário a troca dos drenos, por drenos 
de no mínimo $10 \mathrm{~cm}$ de diâmetro, com pontas em bisel, ultrapassando no mínimo $15 \mathrm{~cm}$ da laje. É necessário também reparos no pavimento para a correta confluência das águas para os drenos, evitando acúmulos.

Observou-se ainda a inexistência de pingadeiras nas bordas da viga longarina, o que proporcionou, durante os anos, a presença de manchas escuras em toda a face externa da peça estrutural, conforme mostra a figura 10. Por isso, necessita-se de instalações de estruturas nas bordas com pingadeiras para evitar permanência de umidade.

\section{Encontros e aterro de acesso}

Segundo PFEIL (1983) encontros são estruturas cuja sua principal função é resistir à empuxos provenientes do aterro de acesso, de forma a evitar que esses esforços cheguem até os outros elementos da ponte. $O$ elemento também impede que ocorra a erosão do aterro de acesso. São imprescindíveis em pontes devido à constante dinâmica de cargas advinda do aterro, e também advindas de erosões provocadas pelas águas, principalmente em períodos de cheia.

Na ponte em estudo, a estrutura de contenção de aterro, ou saia de aterro, está em balanço e engastada na viga longarina. Desta forma, os esforços provenientes do empuxo do aterro de acesso são transmitidos à viga, que por sua vez os transmite aos pilares. As consequências destas transferências de cargas a mesoestrutura serão tratadas nos itens sobre Aparelhos de Apoio e Pilares.

A estrutura de contenção também se encontra evidentemente insuficiente, com dimensões diminutas para a contenção do aterro. Isto ocasionou erosões localizada nos encontros da ponte. A Figura 11.a, mostra a erosão completa no pé do aterro. Já a figura 11.b mostra a erosão no segundo encontro, junto à estrutura de madeira provavelmente instalada em uma intervenção afim de conter a erosão.

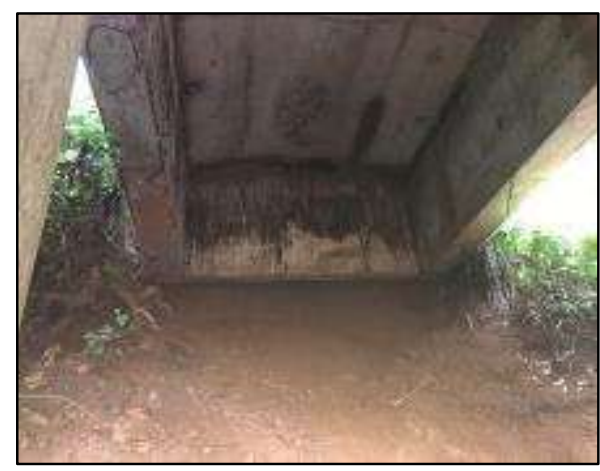

a)

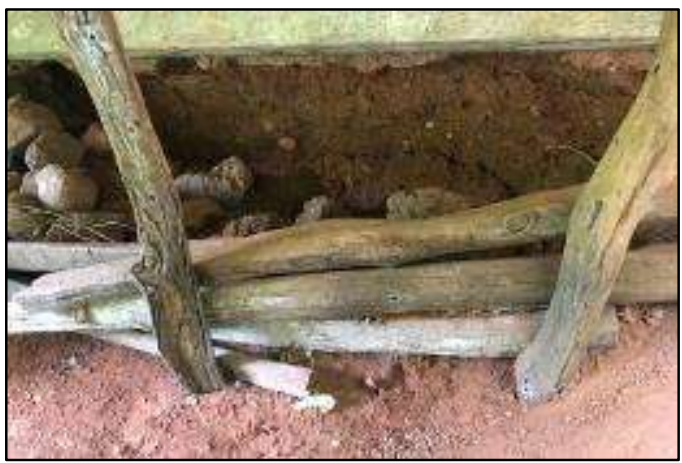

b)

Figura 11 (a - b): Erosão localizada nos encontros.

Segundo Cardoso (2008), a erosão localizada, também conhecida como fossas de erosão são desenvolvidas em torno dos pilares e encontros (Figura 12). Essa erosão é ocasionada principalmente no período de cheias. A ação das enchentes aumenta a pressão dinâmica transversal aos pilares e encontros, e os impactos podem ser acentuados de acordo com a forma geométrica do elemento, por isso, o poder de destruição de uma cheia é acrescido com falhas no projeto na geometria dos elementos da ponte (VITÓRIO, 2015). Devido ao processo de erosão dos aterros de acesso, ocorreu assentamento, ocasionando discordância entre o tabuleiro da ponte e a rodovia, gerando degrau acentuado, o que gera impactos dos 
veículos na entrada da ponte (Figura 13).

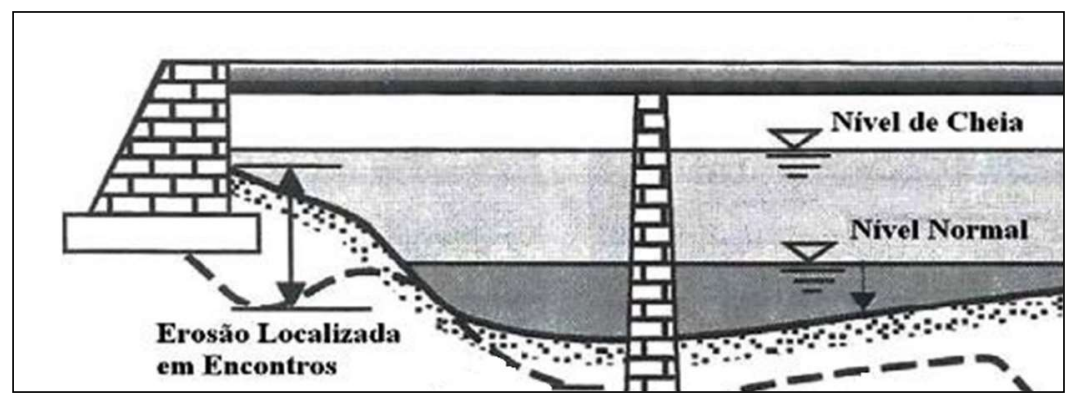

Figura 12: Modelo de erosão localizada nos encontros.

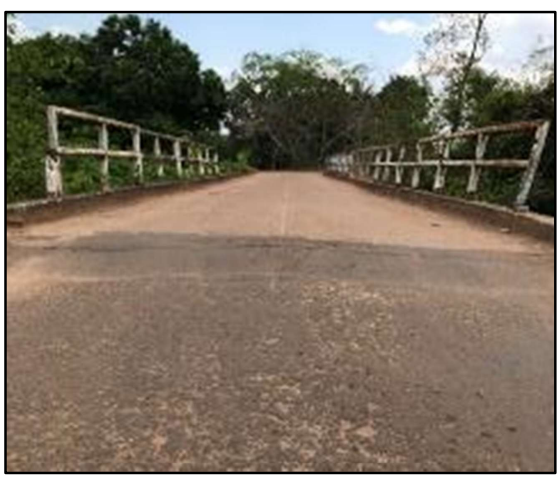

Figura 13: Discordância de nível entre a pista e o tabuleiro.

Tal fator produz, tanto impactos verticais quanto impactos horizontais. Segundo PFEIL (1983) o impacto vertical é aumento da carga móvel causado por deformações no tabuleiro. Dessa forma, é possível afirmar que há ampliação das cargas móveis sobre o tabuleiro da ponte. A solução mais viável, é procurar, através de outras soluções, a contenção do aterro para atuar complementando a deficiência da estrutura de contenção existente. A exemplo, muros de gabiões, disposição de Rip Rap, entres outras soluções de contenção de aterros, optando pelo método mais econômico e viável na região.

\section{Aparelho de apoio}

Segundo DNIT (2006) o aparelho de apoio consiste em dispositivos responsáveis pela transferência de cargas da superestrutura, para a mesoestrutura; tem função também de permitir movimentos longitudinais provenientes da dilatação ou retração devido a fatores físicos, e permite também a rotação no eixo da viga longarina.

$\mathrm{Na}$ figura 14 evidencia-se que o aparelho de apoio, fabricado em elastômero, apresenta esmagamento, provavelmente, pelo uso em cargas superiores às estimadas em projeto. Apresenta também esforços de cisalhamento, demonstrando deflexões. Este fator é devido às forças horizontais, oriundas da transferência de tensões de empuxo da superestrutura para a mesoestrutura acentuadas sobre os pilares devido à instabilidade na região dos encontros.

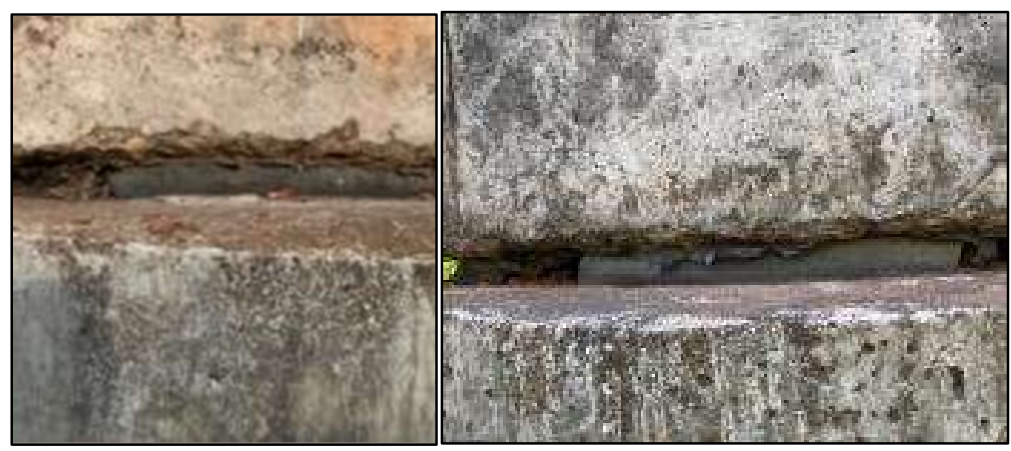

a)

b)

Figura 14 (a - b): Aparelho de apoio com esmagamento e sofrendo esforços cisalhantes.

A figura 15 demonstra, segundo modelo apresentado por Marchetti (2018), o comportamento de 
aparelhos de apoio de elastômeros (Neoprene) quando sujeitos a forças horizontais. Deformam, apresentando ângulo ( $($ ) na face lateral. Este efeito pode ser de curta duração e longa duração.

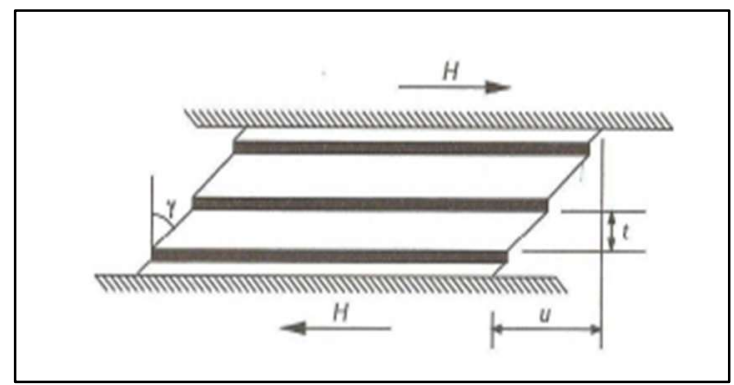

Figura 15: Modelo de aparelho de apoio Neoprene sujeitos a esforços horizontais. Fonte: Marchetti (2018).

Ainda que aparelhos de apoio apresente patologias, o DNIT (2006) aponta que devido à dificuldade e custos de substituição, é necessário antever alguns quesitos antes da troca, a citar: se há separação nítida entre a superestrutura e a mesoestrutura; se há defeitos que ocasionem danos ao sistema estrutural da ponte; ou se há fissuras localizadas próximo ao apoio.

Deste modo, é possível postergar a troca do aparelho de apoio da ponte em estudo, porém, quanto as tensões de cisalhamento devem-se corrigir através da estabilidade dos encontros, e quanto ao esmagamento, deve se fazer ensaios de provas de carga sobre a estrutura da ponte afim de certificar o uso de cargas superiores às projetadas.

\section{Pilares}

A figura 16 mostra o desaprumo dos pilares, provavelmente, devido às tensões horizontais causadas pela instabilidade das estruturas de encontro, acentuadas pelos esforços horizontais originadas dos veículos.



Figura 16: Deformação pilares deformados às tensões horizontais - verificação do prumo.

Segundo Pfeil (1983) os esforços horizontais são provocados pela aceleração, frenagem e por empuxos de terra advindo do aterro de acesso, e são absorvidos pelas estruturas de encontro (saias de aterro), e pelos pilares. A variação das reações provenientes do empuxo dos aterros atuantes na estrutura de contenção, que é engastada na viga longarina, advinda da falta de estabilidade provocada pela erosão do 
aterro, transmite cargas horizontais acentuadas para os pilares e os deformam, o que é evidenciado pelo seu desaprumo. É necessário, a partir de um estudo mais profundo, avaliar a estabilidade do pilar. Já a estabilidade dos aterros, se faz necessário em critério de urgência, para evitar que tais tensões continuem intensa sobre os pilares, instabilizando-os ainda mais.

\section{Presença de agentes bióticos}

Os principais efeitos patológicos dos agentes bióticos são os efeitos físicos nos elementos e a presença de umidade. Apesar de serem bem mais danosos nas estruturas de madeira, ainda podem causar danos ao concreto de acordo com o tempo de ação. Representados, por exemplo, pelos fungos, besouros, cupins e morcegos, necessitam de algumas condições para a sobrevivência como a temperatura, oxigênio, umidade e fonte adequada de alimentação (SARTORTI, 2008). A ponte em estudo apresenta dois agentes bióticos em predominância, os morcegos e cupins. Os cupins se manifestam na parte inferior da laje em toda a extensão da ponte, assim como nas vigas e nos pilares (Figura 17).

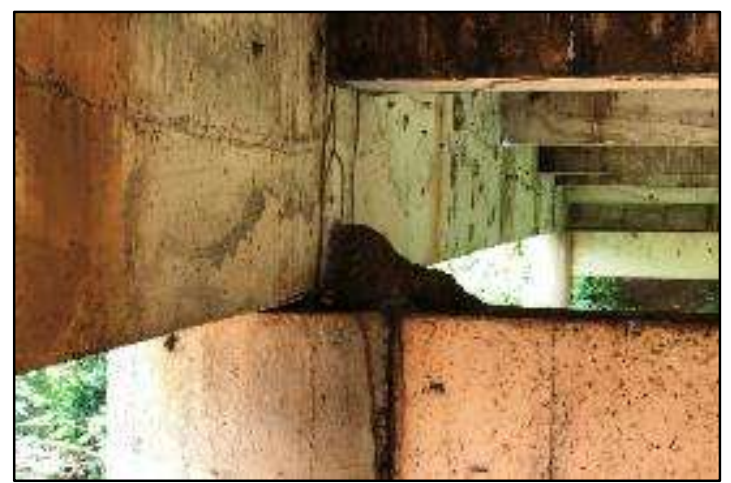

Figura 17: Presença de cupins na estrutura.

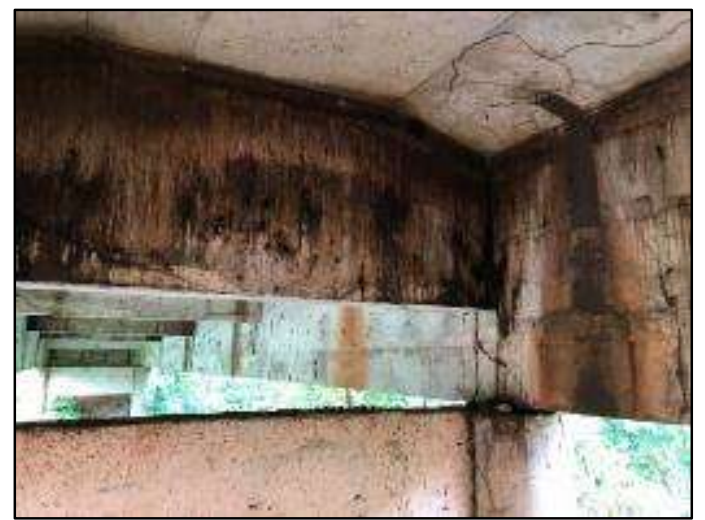

Figura 18: Excreções de morcego na ponte.

Já as manifestações de morcegos estão concentradas na parte da parte inferior próximos aos encontros, onde dispõe de pouca luz. A presença de morcegos causa umidade ininterrupta sobre as peças estruturas da ponte, oriundos das excreções. Evidenciadas por manchas escuras na peça estrutural, apresentadas na figura 18. A presença de umidade sobre a estrutura é prejudicial ao concreto. Podendo diminuir a vida útil da estrutura.

Para evitar patologias oriundas de agentes biológicos é necessário fazer limpezas periódicas, afim de evitar que tais vetores se instalem por intervalos de grande tempo. Essas limpezas podem ser feitas através de produtos químicos, no caso do cupim, afim de exterminá-los, e manter o espaço limpo, destituídos de entulhos ou madeiras, de modo a evitar fonte de alimento para este agente. Já no caso dos morcegos é necessário a retiradas dos excrementos através de jateamento sobre as estruturas afetadas. Devido à dificuldade da retida desse a gente, a frequência dessas ações deve ser maior.

\section{CONCLUSÕES}

O trabalho pôde mostrar que ao decorrer de quase três décadas, a falta de manutenção foi bastante danosa à estrutura. Dado os objetivos do trabalho, foi possível visualizar e caracterizar todas as peças 
estruturais da ponte, identificando as possíveis patologias visualmente e através de registros fotográficos. Com base nos resultados obtidos, a ponte demonstra insuficiência diante a demanda de fluxo de transito atual, visto que é executada em apenas uma via, também foi constatado uma possível sobrecarga no aparelho de apoio e suas vigas longarinas apresentam sobre si agentes prejudiciais no concreto. $\mathrm{O}$ sistema de drenagem, encontra-se insuficiente, com capacidade parcial de escoamento das águas. Quanto ao sistema estrutural, a ponte apresenta instabilidade nas regiões de encontro onde ocasiona efeito cascata sobre os elementos da mesoestrutura e infraestrutura.

No geral, as patologias encontradas nos elementos da ponte não demonstraram sinais de insuficiência estrutural, a ponto de haver risco de colapso da estrutura. Porém, a ineficiência dos dispositivos de segurança e sinalização tem sido ponto crucial para as estimativas de acidentes, pondo em perigo os usuários, logo, é de grande importância uma intervenção imediata afim de garantir um trafego seguro no local. Por fim, este trabalho sugere recomendações necessárias para as possíveis patologias presentes na estrutura. Reforçando a necessidade de intervenção e de ações preventivas, por meio de inspeções rotineiras, uma vez que, a falta destas ações reduz a vida útil da estrutura.

\section{REFERÊNCIAS}

ABNT. Associação Brasileira de Normas Técnicas. NBR 6118:2014. Projeto de estruturas de concreto Procedimento. Rio de Janeiro: ABNT, 2014.

ABNT. Associação Brasileira de Normas Técnicas. NBR 9452:2019: Inspeção de pontes, viadutos e passarelas de concreto - Procedimento. Rio de Janeiro: ABNT, 2019

CAMPOS, V. C.; LABRE, C. V.; COSTA, L. P.; CARVALHO, D. I. Inspeção de uma ponte de acordo NBR 9452, na cidade de Palmas - TO: análise das manifestações patológicas. Revista Científica Multidisciplinar Núcleo do Conhecimento, v.2, p.98-109, 2018

CARDOSO, R. A. F.. Infraescavação em pilares de pontes. Dissertação (Mestrado) - Universidade de Aveiro, Lisboa, 2008.

DNIT. Departamento Nacional de Infraestrutura de Transportes. Norma DNIT 010/2004- PRO. Inspeções em pontes e viadutos de concreto armado e protendido Procedimento. Rio de Janeiro: DNIT, 2004.

DNIT. Departamento Nacional de Infraestrutura de Transportes. Norma DNIT 088/2006- ES. Dispositivos de segurança lateral: guarda-rodas, guarda-corpos e barreiras Especificação de Serviço. Rio de Janeiro: DNIT, 2006.

DNIT. Departamento Nacional de Infraestrutura de Transportes. Norma DNIT 091/2006: Tratamento de aparelhos de apoio: concreto, neoprene e metálicos especificação e serviços. Rio de Janeiro: DNIT, 2006.
Transportes. Norma DNIT 122/2009-ES. Pontes e viadutos rodoviários - Estruturas de concreto armado - Especificação de serviço. Rio de Janeiro: DNIT, 2009.

DNIT. Departamento Nacional de Infraestrutura de Transportes. Diretoria Executiva. Instituto de Pesquisas Rodoviárias. Manual de sinalização rodoviária. 3 ed. Rio de Janeiro: DNIT, 2010.

FELIPPE FILHO, W. N.. Avaliação dos coeficientes de impacto utilizados no cálculo de pontes rodoviárias via análise dinâmica de estruturas. Monografia (Trabalho de Conclusão de Curso). Universidade Federal de Juiz de Fora, Juiz de Fora, 2008.

MARCHETTI, O.. Pontes de concreto armado. 2 ed. São Paulo: Blucher, 2018.

MILANI, C. J.; KRIPKA, M.. A identificação de patologias em pontes de madeira: Diagnóstico realizado no sistema viário do município de Pato Branco - Paraná. Revista Eletrônica de Engenharia Civil, v.1, n.4, p.23-33, 2012.

PFEIL, W.. Pontes em concreto armado. 3 ed. Rio de Janeiro: LCT, 1983

SARTORTI, A. L.. Identificação de patologia em pontes vias urbanas e rurais no município de Campinas - SP. Campinas, 2008.

VITÓRIO, J. A. P.. Fundamentos da erosão nas fundações de pontes e nos aterros de acesso. Recife: Escola Politécnica da Universidade de Pernambuco, 2014.

DNIT. Departamento Nacional de Infraestrutura de

A CBPC - Companhia Brasileira de Produção Científica (CNPJ: 11.221.422/0001-03) detém os direitos materiais desta publicação. Os direitos referem-se à publicação do trabalho em qualquer part do mundo, incluindo os direitos às renovações, expansões e disseminações da contribuição, bem como outros direitos subsidiários. Todos os trabalhos publicados eletronicamente poderão posteriormente ser publicados em coletâneas impressas sob coordenação da Sustenere Publishing, da Companhia Brasileira de Produção Científica e seus parceiros autorizados. Os (as) autores (as) preservam os direitos autorais, mas não têm permissão para a publicação da contribuição em outro meio, impresso ou digital, em português ou em tradução. 